diagnosis has been confirmed. In this case not treating the traumatic diaphragmatic rupture for a long period caused a very rare complication. Arriving at the diagnosis of diaphragmatic rupture was difficult because we did not consider the possibility of diaphragmatic rupture causing lung lobar torsion. However, torsion was suggested by the opacity observed in the left lung on the chest radiogram and the nearcomplete occlusion of the bronchus revealed by means of bronchoscopy. ${ }^{1-3}$ It is important to consider that lung lobar torsion can occur as a a result of diaphragmatic rupture, and repair should be performed before lung lobar torsion occurs.

\section{References}

1. Cable DG, Deschamps C, Allen MS, Miller DL, Nichols FC, Trastek VF, et al. Lobar torsion after pulmonary resection: presentation and outcome. J Thorac Cardiovasc Surg. 2001;122:1091-3.

2. Kanaan S, Boswell WD, Hagen JA. Clinical and radiographic signs lead to early detection of lobar torsion and subsequent successful intervention. J Thorac Cardiovasc Surg. 2006;132:720-1.

3. Sticco CC, Andaz S, Fox S. Middle lobe torsion after right upper lobectomy: a report of video-assisted thoracoscopic management. $J$ Thorac Cardiovasc Surg. 2007;134:1090-1.

4. Reber PU, Schmied B, Seiler CA, Baer HU, Patel AG, Buchler MW. Missed diaphragmatic injuries and then long-term sequelae. J Trauma. 1998;44: 183-8.

5. Wiencek RG, Wilson RF, Steiger Z. Acute injuries of the diaphragm: an analysis of 165 cases. J Thorac Cardiovasc Surg. 1986;92:989-93.

\title{
Heparin-induced thrombosis without thrombocytopenia
}

\author{
Frederick A. Tibayan, MD, ${ }^{\mathrm{a}}$ Lawrence L. Leung, MD, ${ }^{\mathrm{b}, \mathrm{c}}$ Thomas A. Burdon, MD, ${ }^{\mathrm{a}, \mathrm{d}}$ and \\ James I. Fann, MD, ${ }^{\text {a,d }}$ Stanford and Palo Alto, Calif
}

Heparin-induced thrombocytopenia (HIT) is a prothrombotic complication of heparin therapy mediated by antibodies that recognize platelet factor 4/heparin complexes and cause platelet activation and thrombin generation. Early recognition of HIT and treatment with non-heparin anticoagulants are essential in reducing thrombotic events, but diagnosis of HIT in patients postcardiac surgery may be confounded by thrombocytopenia because of bleeding, infection, drugs, or intraaortic balloon pump counterpulsation. Furthermore, postoperative thrombocytosis after cardiac surgery may mask platelet consumption because of HIT. ${ }^{1}$

HIT is typically suspected in patients with thrombosis or thrombocytopenia, usually defined as a platelet count less than $100,000 / \mu \mathrm{L}$ or relative decrease of $30 \%$ to $50 \% .^{2-5}$ We present a patient in whom HIT developed without thrombocytopenia after off-pump coronary artery bypass grafting.

\section{CLINICAL SUMMARY}

A 55-year-old man with coronary artery disease, diabetes mellitus, hyperlipidemia, and hypertension presented with

From the Department of Cardiothoracic Surgery, ${ }^{\mathrm{a}}$ Department of Medicine, Division of Hematology, ${ }^{b}$ Stanford University, Stanford, Calif and Section of Hematology ${ }^{c}$ and Cardiothoracic Surgery, ${ }^{\mathrm{d}}$ VA Palo Alto HCS, Palo Alto, Calif.

Disclosures: None.

Received for publication June 4, 2008; accepted for publication July 4, 2008; available ahead of print Sept 22, 2008.

Address for reprints: James I. Fann, MD, 300 Pasteur Drive, Stanford, CA 94305-5247 (E-mail: jfann@stanford.edu).

J Thorac Cardiovasc Surg 2010;139:e6-7

0022-5223/\$36.00

Crown Copyright (C) 2010 Published by Elsevier Inc. on behalf of The American Association for Thoracic Surgery

doi:10.1016/j.jtcvs.2008.07.006 an acute coronary syndrome. Coronary angiogram demonstrated multivessel coronary artery disease. He was placed on a heparin drip. The following day, he underwent a 2-vessel off-pump coronary artery bypass, during which he received 15,000 units of unfractionated heparin intravenously. He was given no heparin postoperatively. On postoperative day 2, his platelet count decreased from 213 to $168 \mathrm{~K} / \mu \mathrm{L}$ (Figure 1). A heparin-induced antibody test was sent, the result of which was negative.

On postoperative day 12 , computed tomography of the chest, which was obtained to evaluate a fever, decrease in oxygen saturation to $93 \%$, and mild increase in heart rate, demonstrated a saddle pulmonary embolus (Figure 2). The patient was otherwise asymptomatic. Lower-extremity ultrasound showed a thrombus in the left popliteal vein. The patient was anticoagulated with intravenous argatroban after obtaining specimens for and pending results of heparin-induced antibody and heparin-induced platelet aggregation tests. The results of the heparin-induced antibody and heparin-induced platelet aggregation were positive. The transition to oral anticoagulation with warfarin was made, and the patient was discharged on postoperative day 28 . Follow-up computed tomography before discharge demonstrated significant diminution of the pulmonary embolus. He remained well at the 3-month follow-up.

\section{DISCUSSION}

HIT is a life-threatening complication in patients undergoing cardiac surgery. Early detection and anticoagulation may limit morbidity caused by HIT, but the diagnosis of HIT in patients undergoing cardiac surgery is confounded 


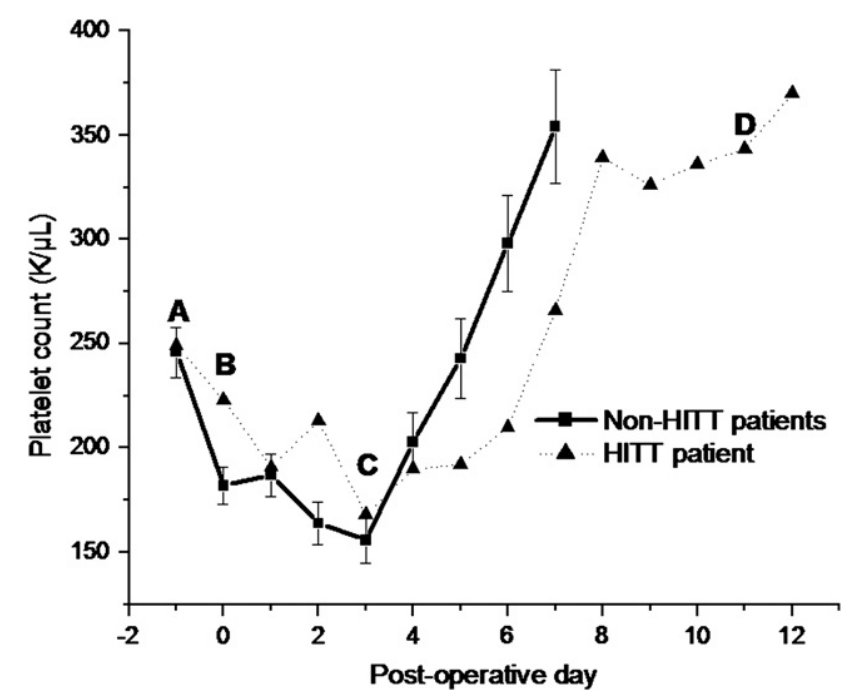

FIGURE 1. Clinical course and platelet count of patient with HIT (dashed line and triangles). A, Admission. B, Immediately after 2-vessel off-pump CABG, $213 \mathrm{~K} / \mu \mathrm{L}$; C, Platelet nadir, $168 \mathrm{~K} / \mu \mathrm{L}$ (heparin-induced antibody negative at this time). D, CT of chest with saddle pulmonary embolus (heparin-induced antibody and heparin-induced platelet aggregation positive). Mean platelet count \pm standard error of the mean of 21 consecutive patients who underwent off-pump coronary artery bypass during same time period as patient with HIT (solid line and squares). HITT, Heparin-induced thrombocytopenia and thrombosis.

by other causes of thrombocytopenia. Also, the reactive thrombocytosis often seen in the normal postoperative course may mask immune-mediated platelet consumption. Furthermore, although the platelet count profile after onpump cardiac surgery has been described, ${ }^{1,3}$ the changes in platelet count after off-pump cardiac surgery are less well understood.

Pouplard and colleagues ${ }^{3}$ described 2 patterns of thrombocytopenia used to predict the development of pathogenic heparin-dependent antibodies after cardiopulmonary bypass: decrease in platelet count after correction of thrombocytopenia occurring during cardiopulmonary bypass and persistent thrombocytopenia in the days after cardiopulmonary bypass. A large saddle pulmonary embolus developed in the patient in this report, with positive studies for heparin-induced antibody and heparin-induced platelet aggregation, but he was not thrombocytopenic. His platelet nadir was $168 \mathrm{~K} / \mu \mathrm{L}$, and he never had a significant relative decrease in platelet count. In fact, the test for heparin-induced antibody on postoperative day 2 (at the time of his nadir) was negative. Of note, this patient was never placed on cardiopulmonary bypass, perhaps explaining why he did not fit into the patterns previously described for on-pump cardiac surgery. Figure 1 shows the platelet count of this patient along with the mean platelet count of 21 other consecutive, contemporaneous patients who had off-pump coronary artery bypass at our institution (Palo Alto VA Hospital).

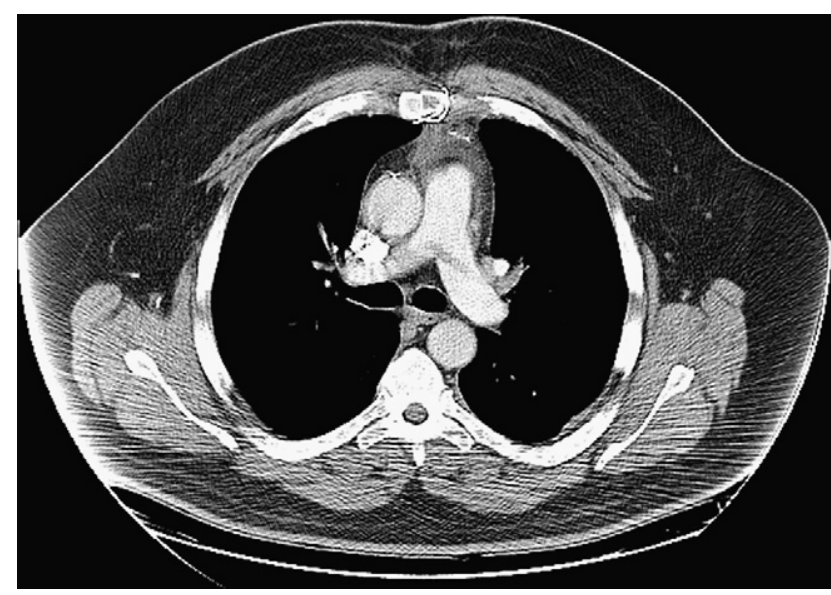

FIGURE 2. Computed tomography of the chest obtained on postoperative day 12 demonstrating a large saddle pulmonary embolus. Tests for heparininduced antibody and heparin-induced platelet aggregation were both positive at this time, although the patient was not thrombocytopenic and never had a significant decrease in platelet count.

Note that both curves have a similar shape with a nadir at approximately postoperative day 3 , followed by an increase to well above preoperative levels.

\section{CONCLUSIONS}

We suggest that thrombocytopenia may be an unreliable indicator of HIT after cardiac surgery (particularly off-pump), and that prospective studies are needed to refine diagnostic criteria for HIT in this difficult population. Until then, we recommend a high index of suspicion for HIT in patients undergoing cardiac surgery and consideration of an alternative anticoagulant to heparin to treat vascular thrombosis pending the results of heparin-induced antibody and heparin-induced platelet aggregation.

\section{References}

1. Selleng S, Seleng K, Wollert HG, Muellejans B, Lietz T, Warkentin TE, et al Heparin-induced thrombocytopenia in patients requiring prolonged intensive care unit treatment after cardiopulmonary bypass. J Thromb Haemost. 2008;6: 428-35.

2. Greinacher A, Farner B, Kroll H, Kohlmann T, Warkentin TE, Eichler P. Clinical features of heparin-induced thrombocytopenia including risk factors for thrombosis. A retrospective analysis of 408 patients. Thromb Haemost. 2005; 94:132-5.

3. Pouplard C, May MA, Regina S, Marchand M, Fusciardi J, Gruel Y Changes in platelet count after cardiac surgery can effectively predict the development of pathogenic heparin-dependent antibodies. Br J Haematol. 2005; 128:837-41.

4. Warkentin TE, Roberts RS, Hirsh J, Kelton JG. An improved definition of immune heparin-induced thrombocytopenia in postoperative orthopedic patients. Arch Intern Med. 2003;163:2518-24.

5. Warkentin TE, Greinacher A. Heparin-induced thrombocytopenia: recognition, treatment, and prevention: the Seventh ACCP Conference on Antithrombotic and Thrombolytic Therapy. Chest. 2004;126:311S-37S. 